\title{
INFLUENCE OF NON-METALLIC INCLUSIONS IN PIPE STEELS OF STRENGTH CLASS X65-X80 ON VALUES OF IMPACT TOUGHNESS OF FLASH-BUTT WELDED JOINTS
}

\author{
S.I. KUCHUK-YATSENKO, Yu.V. SHVETS and V.I. SHVETS \\ E.O. Paton Electric Welding Institute, NASU \\ 11 Bozhenko Str., 03680, Kiev, Ukraine. E-mail: office@paton.kiev.ua
}

\begin{abstract}
The comprehensive mechanical tests of high-strength steel pipe joints produced using flash-butt welding were carried out. The quality of joints completely meets the requirements of the international standard API STANDARD 1104. During tests on impact bending the single dropouts of $K C V-40$ values lower than the level required by standards DNV-OS-F101 and STO Gazprom 2-3.7-380-2009 were observed. The decrease in $K C V_{-40}$ was predetermined by formation of zones of $1-2 \mathrm{~mm}^{2}$ area in the plane of a joint differed by structural heterogeneity, which is characteristic also for base metal and revealed in a sharply distinct anisotropy of its ductile properties. It is shown that the areas with structural heterogeneity do not form colonies, therefore they do not decrease the general serviceability of the welded joint. The sizes of such areas do not exceed the admissible values accepted by the standards for defects of welds made by arc welding. The presence of single local dropouts of $K C V-40$ values observed during tests of welded joints produced using FBW should not be considered as a sign of rejection. 8 Ref., 1 Table, 11 Figures.
\end{abstract}

$\boldsymbol{K} \boldsymbol{e} \boldsymbol{y} \boldsymbol{w} \boldsymbol{o r d} \boldsymbol{s}:$ flash-butt welding, high-strength steel, impact toughness of welded joints, heat treatment of welds

The many-year works in flash-butt welding (FBW) of large-diameters pipes [1] at the E.O. Paton Electric Welding Institute have found the further development over the recent years. The technology of FBW of thick-walled pipes of 1219-1420 mm diameter of high strength steels used in construction of modern pipelines of high efficiency was developed. The technology of welding and heat treatment provides the joints with high values of mechanical properties, which meet the requirements of international standards [2-4]. Basing on this technology CJSC «Pskovelektrosvar» (Russia) jointly with the E.O. Paton Electric Welding Institute developed a new generation of equipment for $\mathrm{FBW}$ of pipes of 1219-1420 mm diameter. At the present time the comprehensive tests of this equipment and weld- ing technology and its adaptation to standard requirements specified for the quality of welded joints during construction of off-shore and onshore pipelines including under conditions of the Extreme North are carried out.

For such pipelines the International standards $[3,4]$ specified the standard values of impact toughness of welded joints of circumferential welds of not less than $37.5 \mathrm{~J} / \mathrm{cm}^{2}$ at the test temperature, which should be $20{ }^{\circ} \mathrm{C}$ lower than the design temperature of pipeline service.

The aim of the present article is determination of factors, which influence the value and stability of values of impact toughness of high-strength steel pipe joints produced by FBW.

The development of welding technology was carried out on the sectors of pipes of $1219 \mathrm{~mm}$ diameter with the wall thickness of $27 \mathrm{~mm}$, which are manufactured of sheet steel 10G2FB of X70 strength class, produced by controllable rolling

Mechanical properties of metal of pipes and welded joints

\begin{tabular}{||l|c|c|c|c|c|c||}
\hline \multirow{2}{*}{\multicolumn{1}{c|}{ Investigation area }} & \multirow{2}{*}{$\begin{array}{c}\text { Yield strength, } \\
\mathrm{MPa}\end{array}$} & \multirow{2}{*}{$\begin{array}{c}\text { Tensile } \\
\text { strength, MPa }\end{array}$} & \multicolumn{3}{|c||}{ Impact toughness, $\mathrm{J} / \mathrm{cm}^{2}$, at $T,{ }^{\circ} \mathrm{C}$} \\
\cline { 5 - 7 } & & & +20 & -20 & -30 & -40 \\
\hline Base metal & $\frac{484.4-493.5}{490.0}$ & $\frac{546.7-556.8}{553.0}$ & $\frac{334.7-336.6}{335.8}$ & - & - & $\frac{333.0-336.6}{334.9}$ \\
\hline Welded joint after heat treatment & - & $\frac{550.6-561.4}{554.6}$ & $\frac{147.9-219.5}{173.2}$ & $\frac{86.8-171.1}{137.9}$ & $\frac{84.5-167.5}{115.5}$ & $\frac{19.1-129.1}{98.6}$ \\
\hline
\end{tabular}




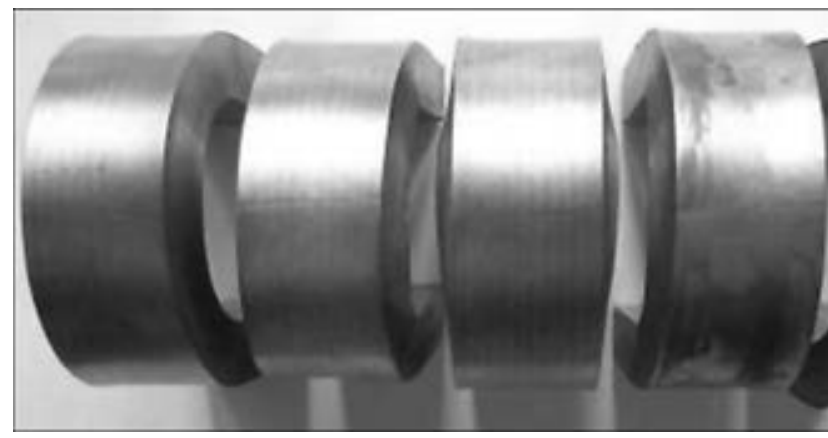

Figure 1. Specimens of welded joint tested on static bending after heat treatment

with thermal mechanical strengthening, of the following chemical composition, wt.\%: $0.06 \mathrm{C}$; $0.21 \mathrm{Si} ; 1.42 \mathrm{Mn} ; 0.12 \mathrm{Ni} ; 0.07 \mathrm{Mo} ; 0.04 \mathrm{~V}$; $0.04 \mathrm{Al} ; 0.02 \mathrm{Ti} ; 0.05 \mathrm{Cr} ; 0.02 \mathrm{Nb} ; 0.004 \mathrm{~S}$; $0.012 \mathrm{P}$. The mechanical properties of base metal and also of welded joints after heat treatment are given in the Table. The modes of welding and heat treatment are presented in [5, 6]. All the welded joints were subjected to non-destructive testing (radiographic, ultrasonic) of a high resolution capacity.

The mechanical tests of welded butts were carried out at the PWI laboratory according to the requirements stated in work [3]. This laboratory is certified according to the International standards. Metallographic examinations were carried out in the light microscope «Neophot-32», analyses of fracture surfaces and microstructure of joints were made in the JEOL Auger-microprobe JAMP 9500F (Japan) in the laboratory of metallographic investigations.

In the specimens, tested for static bending after heat treatment and presented in Figure 1, the cracks and fractures were not detected.

As is seen from the Table and Figures 1, 2 the values of impact toughness in heat-treated welded joints meet the requirements in the temperature range of $+20--30{ }^{\circ} \mathrm{C}[3,4]$, specified for the off-shore pipelines. With the reduction of testing temperature $T_{\text {test }}$ of specimens for bending tests the values of $K C V$ are reduced and scattering of their values increases (see $\mathrm{Fi}^{-}$

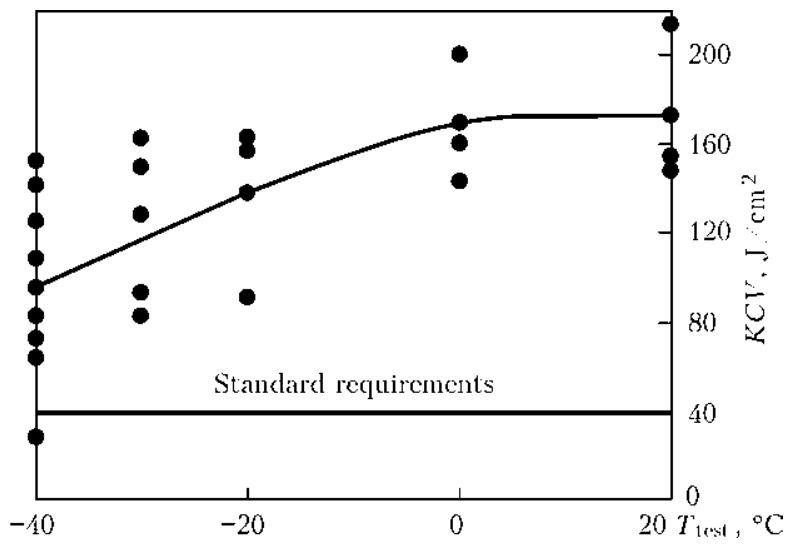

Figure 2. Temperature dependence of impact toughness of welded joints

gure 2). Nevertheless at $T_{\text {test }}=-30{ }^{\circ} \mathrm{C}$ they remain at a sufficiently high level of $84.5-167.5 \mathrm{~J} / \mathrm{cm}^{2}$ and at $T_{\text {test }}=-40{ }^{\circ} \mathrm{C}$, which is envisaged for continental pipelines under the conditions of the Extreme North, scattering of values increases and single dropouts below the level of $37.5 \mathrm{~J} / \mathrm{cm}^{2}$ are observed, regulated by the standard DNVOS-F101. The number of such specimens tested at the mentioned temperature does not exceed 10-15\%. Here, the average value of $K C V$ remains sufficiently high $-98.6 \mathrm{~J} / \mathrm{cm}^{3}$.

The testing of welded joints of all the specimens using non-destructive methods did not detect any imperfections of metal structure in the plane of the joint, which could be classified as defective ones, even at setting up the devices to increased sensibility.

Macro- and microstructure of the pipe joint, produced at the optimal mode with the further heat treatment, are given in Figure 3. The total HAZ width after welding and heat treatment amounts to about $60 \mathrm{~mm}$. The base of microstructure of HAZ metal, as well as base metal is ferrite. Along the joint line the microstructure is featured by somewhat large size of ferrite grain (10$15 \mu \mathrm{m})$ as compared to HAZ microstructure and presence of partially decayed residual austenite with formation of grain bainite.

In the course of comparison of weld microstructure of specimens, which showed minimum

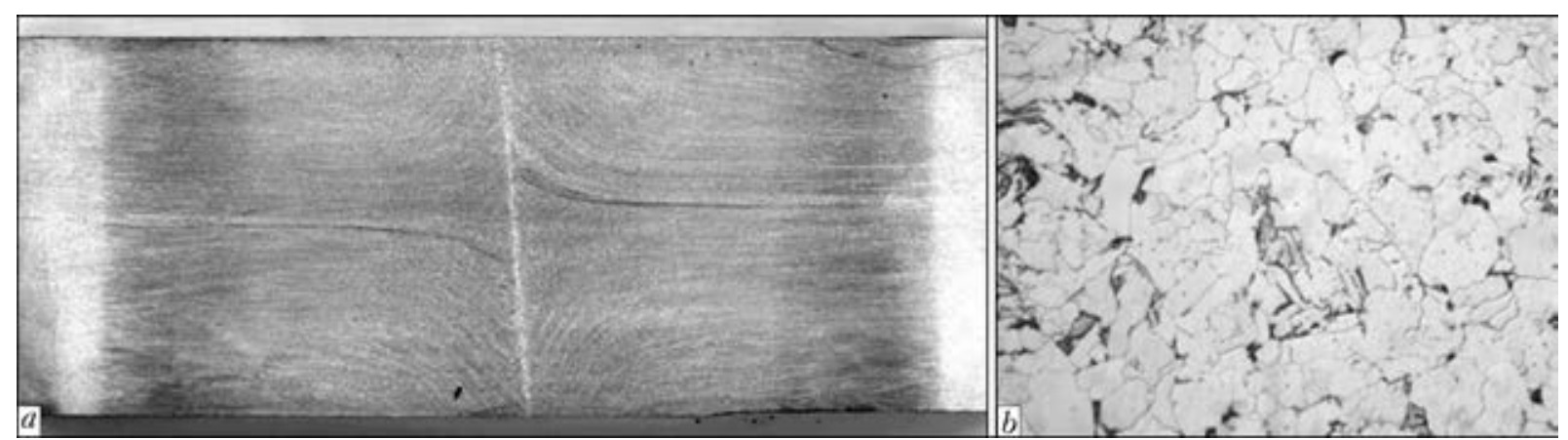

Figure 3. Macro- $(a)$ and microstructure $(b-\times 1000)$ of joints of pipe steel at the area of joint line 

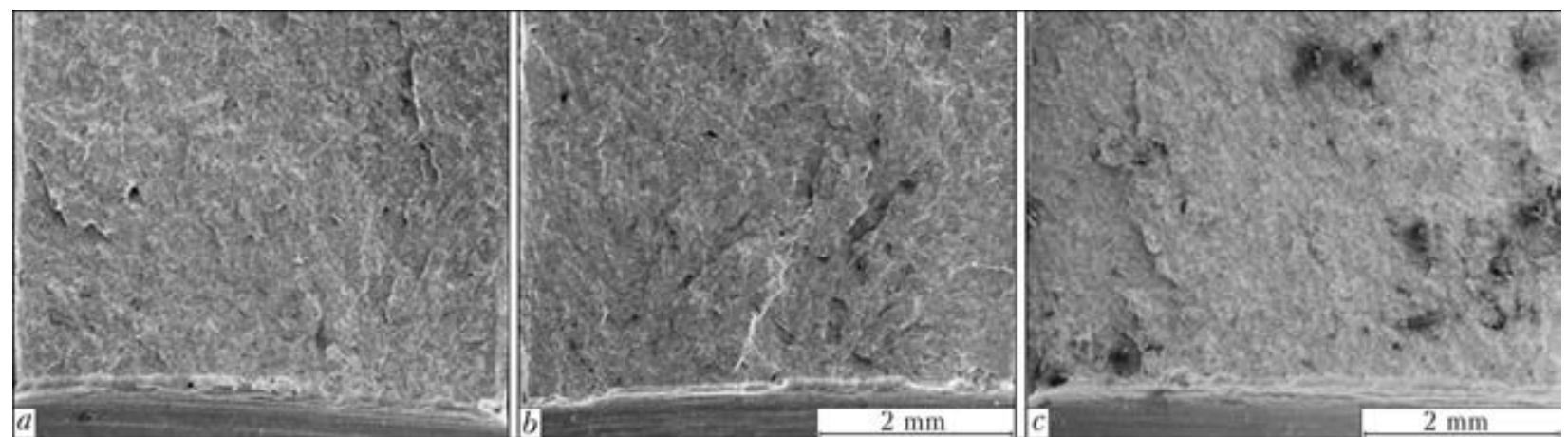

Figure 4. Macrostructure of fractures of welded specimens after impact bending tests: $a-K C V-40=110 ; b-29.1$; $c-19.1 \mathrm{~J} / \mathrm{cm}^{2}$

and maximum values of $\mathrm{KCV}_{-40}$ during tests, no differences were revealed.

The analysis of structure of fractures of welded specimens after tests on impact bending was performed. The investigations showed that fractures of specimens are crystalline in all the cases $(\mathrm{Fi}-$ gure 4). The developed relief in some cases is connected with presence of coarse non-metallic inclusions (NMI) in metal.

Microstructure of fracture surfaces of all the specimens is morphologically the same ( $\mathrm{Fi}^{-}$ gure 5). The facets of chips with the structure elements typical of cleavage fracture, such as steps of river pattern and lugs, are combined with tear ridges, i.e. the elements of tough fracture. The presence of secondary cracks along the interfaces are characteristic.

The impact toughness of specimens with such microstructure at almost absent NMI corresponded to standard requirements (see Figure 4, $a$ ).

In the specimens with a low impact toughness the cluster of NMI was revealed at the fracture surface (see Figure 4,c). X-ray spectral microanalysis of chemical composition allowed distinguishing the following types. These are the complex oxides of silicon, calcium, aluminium of up to $50 \mu \mathrm{m}$ size (Figure 6, spectra 1, 2),

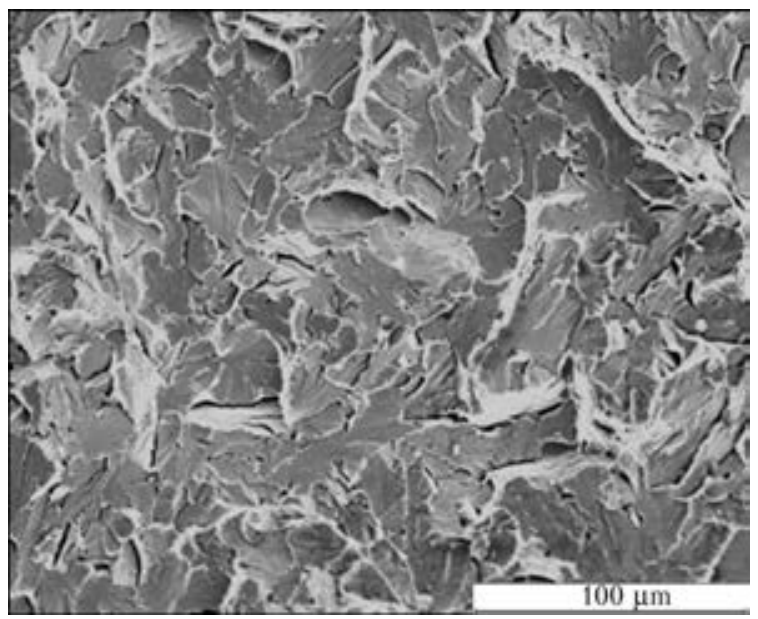

Figure 5. Microstructure of fracture surface of welded specimens after impact bending tests particles on the base of silicon (Figure 6, spectra $3,4)$. These inclusions are refractory products of metallurgical reactions, which transfer to the weld almost without suffering the changes under the thermodeformational conditions of welding. Impurity and alloying elements such as sulfur, niobium and titanium also can be included to their composition.

Another type of the observed inclusions, forming clusters, are silicates. The areas with the particles of silicates, which could be observed, occupied the area up to several square millimeters. The fused appearance and multitude of particles give grounds to suppose that they represent the fragments of a liquid film crushed in a butt ( $\mathrm{Fi}^{-}$ gure 7).

To evaluate the effect of NMI in steel on structure and composition of inclusions in welds, the metallographic examinations of base metal were carried out.

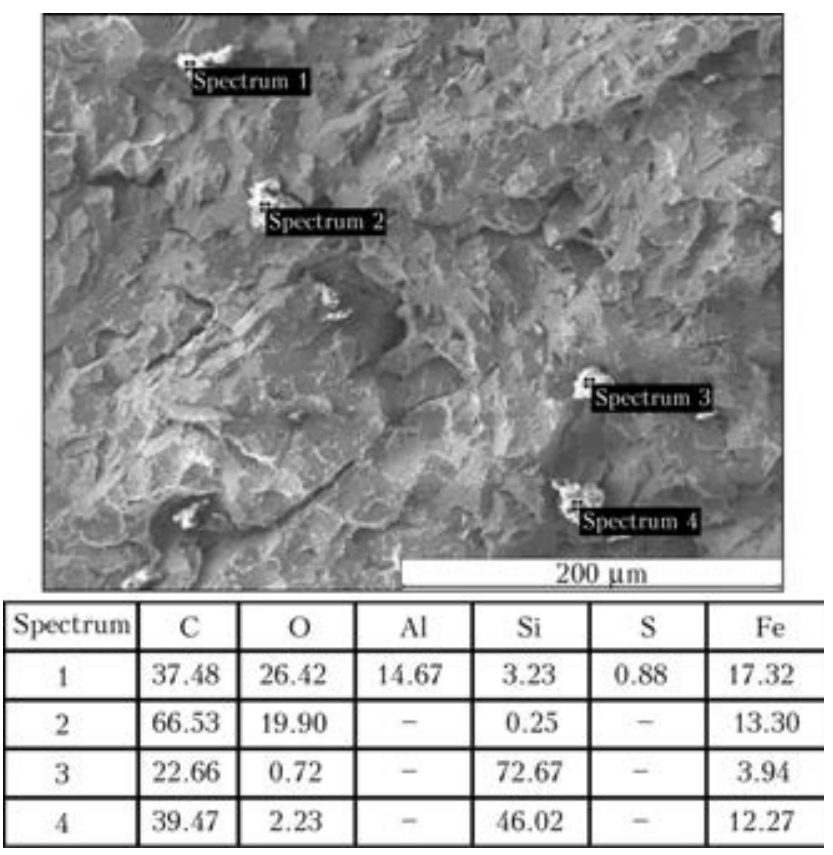

Figure 6. Refractory NMI at the fracture surface of welded joint, and results of their X-ray spectral microanalysis (here and after - at.\%) 


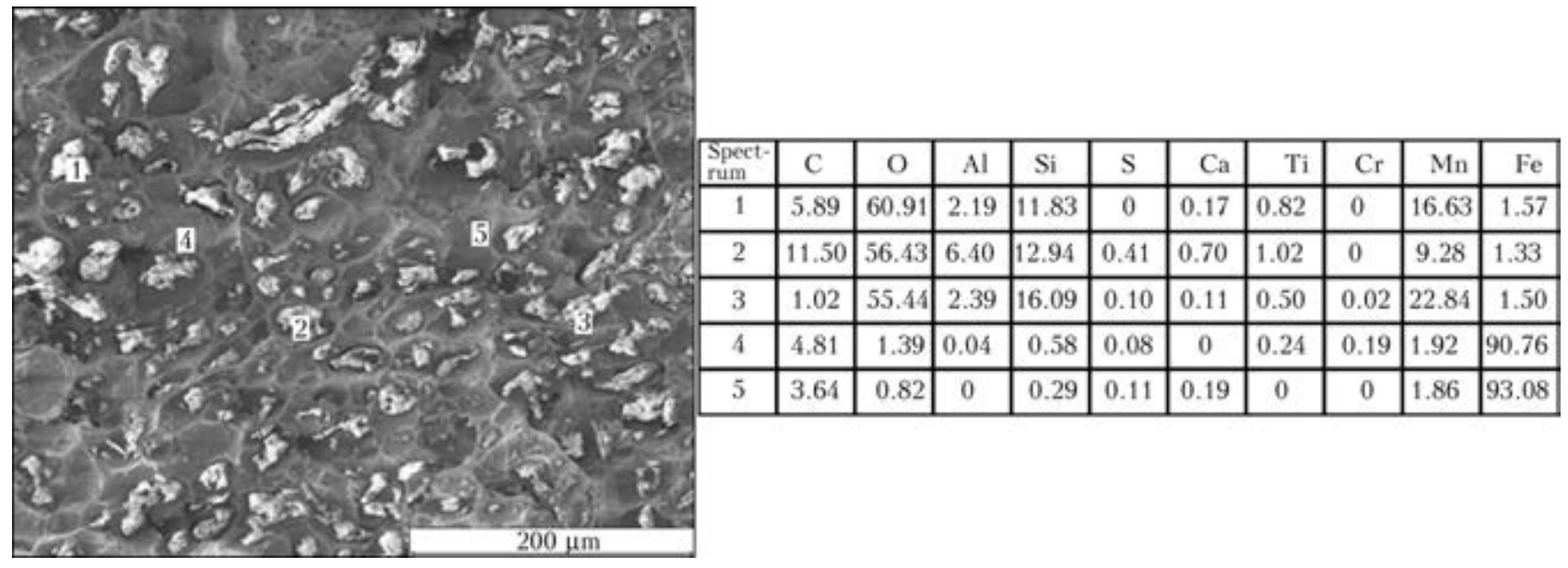

Figure 7. Manganese alumosilicates on the fracture surface of pipe joints

Microstructure of base metal represents a ferrite matrix with negligible amount of pearlite colonies (Figure 8, $a$ ). The size of grains of ferrite amounts by estimation to the limits from several to $10 \mu \mathrm{m}$ (11-12 according to ASTM), here the coarse grains of ferrite are elongated along the direction of rolling. The characteristic is the considerable level of foliation of microstructure, which is observed due to stringer-type location of products of the eutectoid transformation.

NMI which are mainly represented by complex oxides and sulfides of aluminium, silicon, calcium, manganese, iron (Figure $8, b$ ), in microstructure are distributed non-homogeneously and are often concentrated in the strips of rolling.

To determine the influence of structural heterogeneity of the pipe base metal on impact toughness the tests of specimens, cut out from base metal at different position of notch in Charpy specimens relatively to the strips of rolling, were carried out. Thus, in case of notch on the surface of pipe across the direction of rolling at $T_{\text {test }}=-40{ }^{\circ} \mathrm{C}, K C V=(333.0-336.2) / 334.9$, and with notch in the middle of the surface of the pipe end along the central line of rolling, $K C V=(9.8-236.5) / 53.5 \mathrm{~J} / \mathrm{cm}^{2}$.

The impact toughness tests of specimens of base metal with notch along the central line of rolling showed that the results do not meet the requirements $[4,5]$. The characteristic fractures of specimens are shown in Figure 9.

The values of tests of specimens with notch along the strips of rolling differ sharply by the expressed instability. Among nine specimens with notch along the central line of rolling, six ones had the results lower than the required $37.5 \mathrm{~J} / \mathrm{cm}^{2}$ (at minimum value of $9.8 \mathrm{~J} / \mathrm{cm}^{2}$ ). As is seen, in the limits of strip on single areas the impact toughness is high. Local decrease of plastic properties was caused by structure heterogeneity of rolling strips. However, it can not weaken the metal even in the limits of area commeasurable with the sheet thickness.

On the fracture of base metal, opened along the rolling strip, the numerous inclusions are observed (Figure 10). As to their nature they are

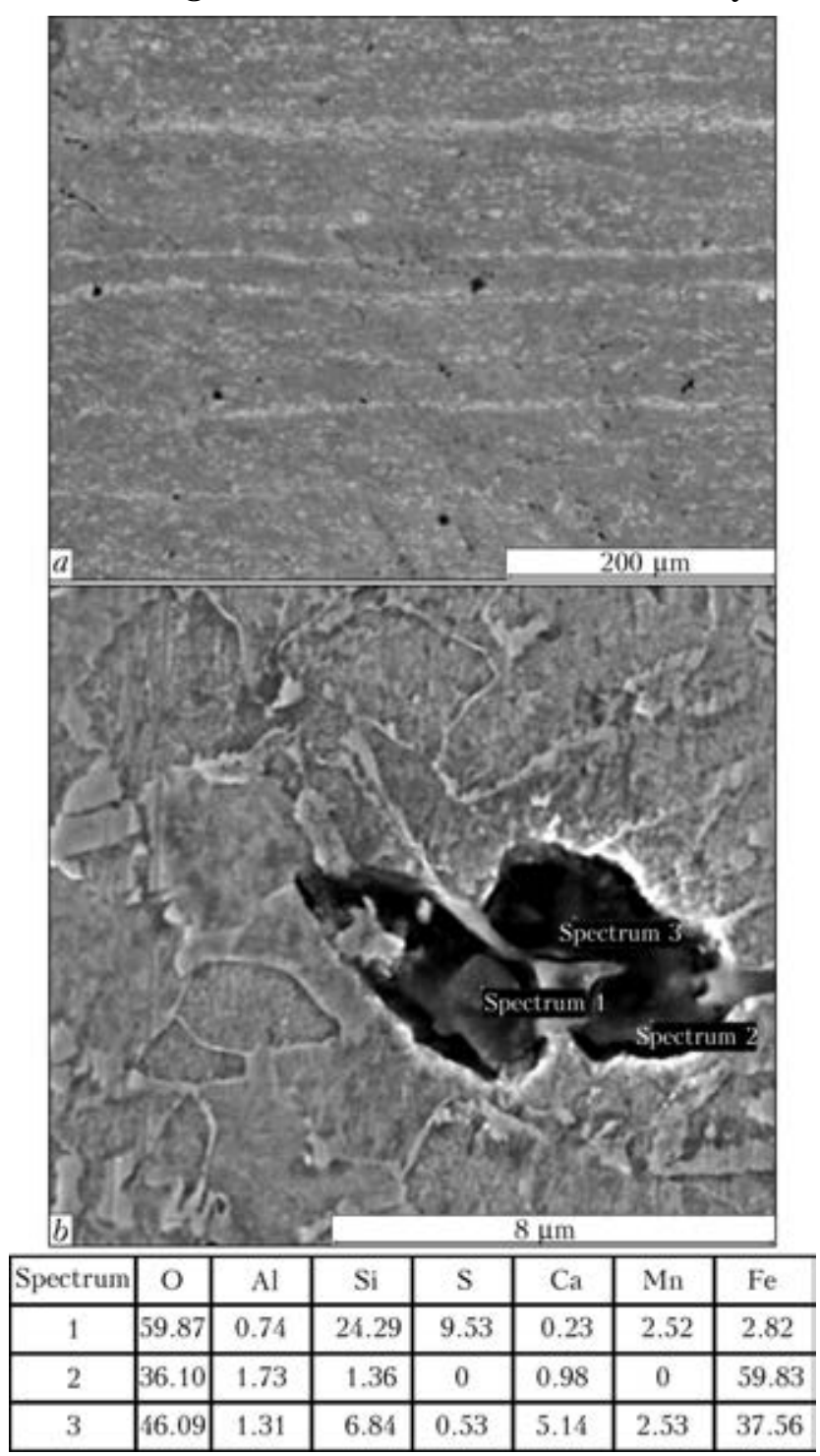

Figure 8. Microstructure of base metal $(a)$, and NMI in base metal $(b)$ 


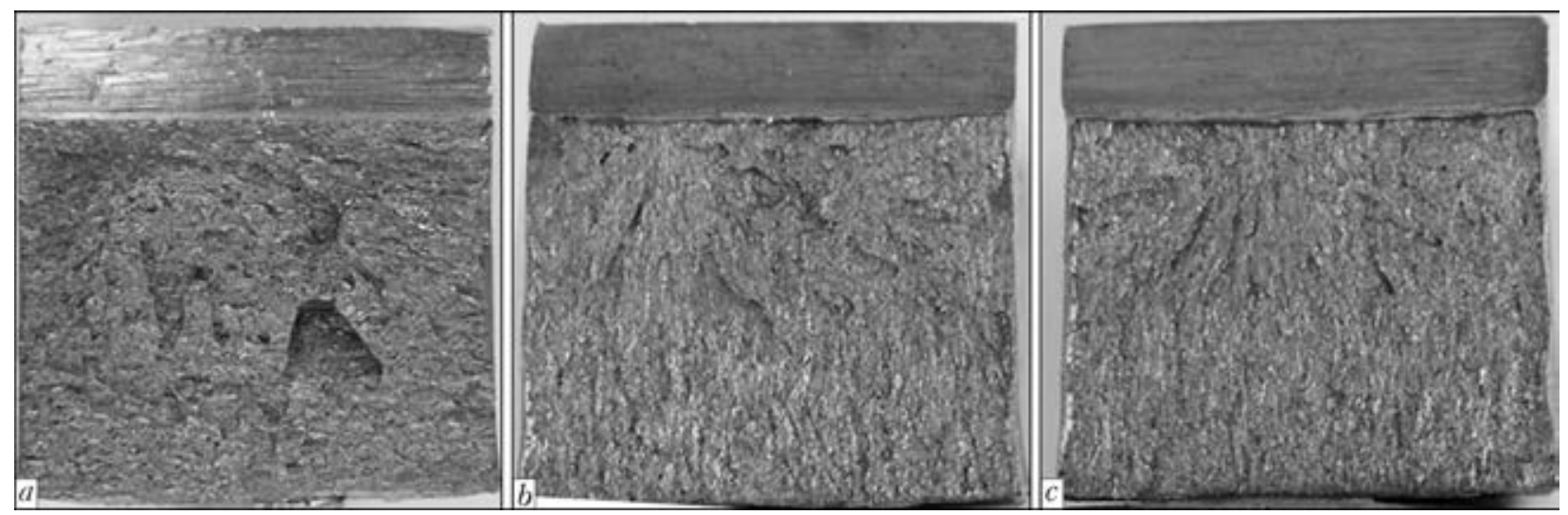

Figure 9. Fracture surface of Charpy impact specimens with notch along the central rolling line: $a-K C V=9.84 ; b-$ $22.2 ; c-30.8 \mathrm{~J} / \mathrm{cm}^{2}$

very close to those observed in the base metal. Their base is oxide structures of silicon, aluminium, manganese, iron oxides and sulfides.

The most obviously that transfer of NMI from the rolling strips to the plane of joint occurs through the melt, being formed on the surface of flashing during welding. The thickness of melt layer during flashing of low-alloyed steels is changed in the limits of $0.1-0.6 \mathrm{~mm}$.

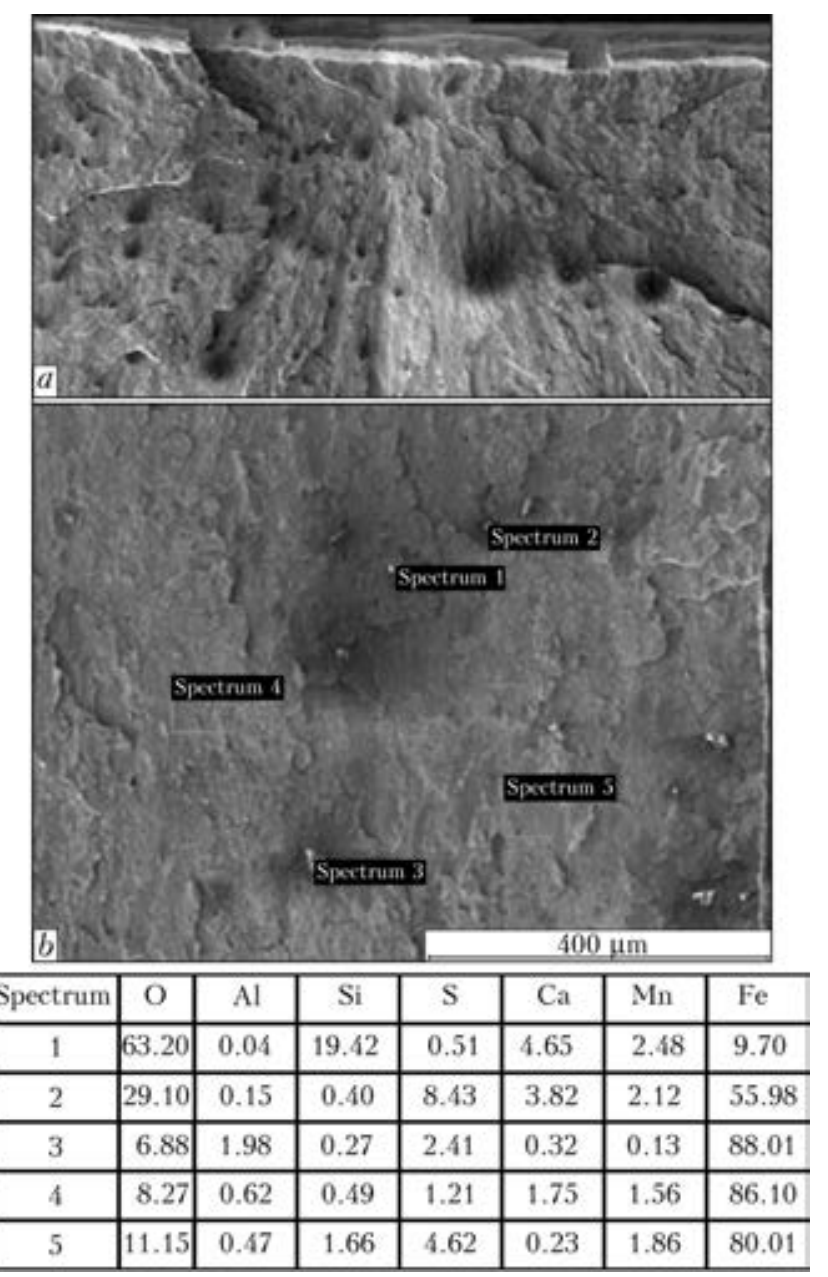

Figure 10. Macro- $(a)$ and microstructure $(b)$ of base metal fracture, opened along the rolling strip, and results of X-ray spectral microanalysis
It is shown in work [7] that at the presence of holes, filled with oxides of iron or any metal fillers, in the part edges being flashed the zone, enriched with filler, is formed in the melt at the places of their escape to the edges being flashed. During upsetting this zone of melt is deformed and its area is many times increased.

In the studied case of formation of structural homogeneity in the plane, the role of filler is played by the content of liquation strip in the place of its escape to the flashing surface.

During evaluation of mechanical properties of welded joints of large-diameter pipes according to the standards $[3,4]$ the values of tests of standard specimens, cut out of sectors of $300 \mathrm{~mm}$ width symmetrically on four regions of pipe perimeter, are considered. Here, the results of mechanical tests and values of non-destructive testing are compared. Basing on the analysis of these data on each sector the conclusion about admission of dropouts of values of mechanical properties and detection of defects is made.

During tests of welded joints of pipes, produced using FBW at the optimal modes, no dropouts from standard requirements on tensile strength and also during tests on static bending were revealed.

To evaluate the distribution of areas with low properties of $K C V$ in the full-scale specimen the coordinate binding of position of impact specimens in the investigated sector of pipe of $300 \mathrm{~mm}$ width was made. Figure 11 shows results of $K C V_{-40}$ along the perimeter and across the thickness of welded butt.

As is seen, the impact specimens with the values lower than the required ones, do not form the colonies, but distributed stochastically in the section of welded joint. Consequently, welded joint will not have the weakened areas noticeably extended from the point of view of values of toughness. 


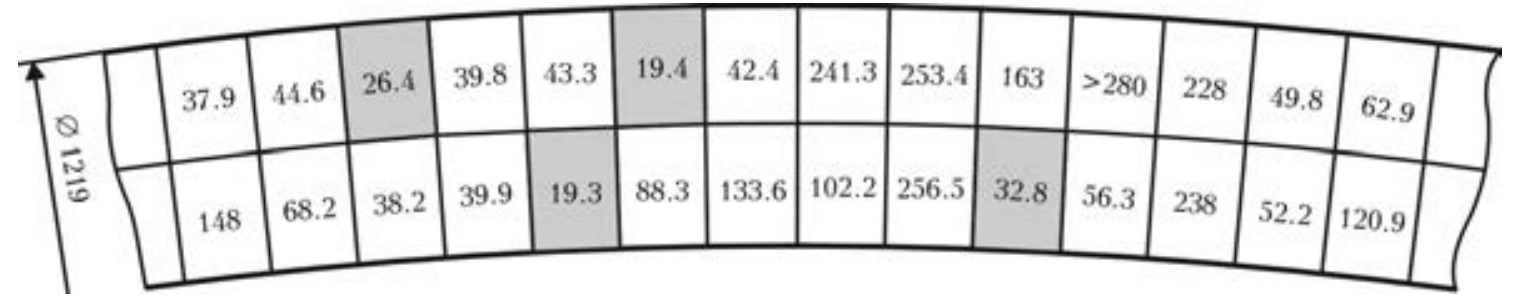

Figure 11. Test results of specimens along the perimeter and across the thickness of welded butt on impact bending at $T_{\text {test }}=-40{ }^{\circ} \mathrm{C}$

All the given data give grounds to suppose that the presence of areas of structural heterogeneity in welded joints and, correspondingly, local decrease in values of impact toughness at the tested zone of welded joint area should not be considered as the rejection mark during evaluation of the quality of joints produced using FBW.

Using standards [4, 8] for electric arc welding the sizes of admissible defects and their total extension at any area of weld of $300 \mathrm{~mm}$ at nondestructive testing are determined. The maximum total length of such areas is $50 \mathrm{~mm}$, and width is up to $1.5 \mathrm{~mm}$ as-applied to the defects of the «lack of penetration» type. Even if one accepts that the areas with structural heterogeneity in FBW are close to lack of penetrations in arc welding, then the mentioned dropouts of values of impact toughness in the butt welds are in the admissible ranges according to the standard. Actually, the mechanical properties of areas with structural heterogeneity are much higher and do not contain discontinuities, where metallic bond is absent at all.

Therefore the presence of single dropouts of values of impact toughness at low test temperatures should not be referred to rejection signs.

\section{Conclusions}

1. The comprehensive mechanical tests of highstrength steel pipe joints produced by FBW were carried out. The quality of joints completely meets the requirements of the International standard API STANDARD 1104. It was found that in impact bending tests the separate dropouts of $K C V_{-40}$ values lower than the level required by standards DNV-OS-F101 and STO Gazprom 2-3.7-380-2009 were observed.

2. Using means of non-destructive testing methods of welded joints, none of welding de- fects was revealed in the joints with low values of $\mathrm{KCV}_{-40}$. It was established that decrease in values of $\mathrm{KCV}_{-40}$ is predetermined by formation of zones of 1-2 $\mathrm{mm}^{2}$ area in the plane of joint characterized by structural heterogeneity, typical also of the base metal, which is revealed in a sharply distinct anisotropy of its ductile properties.

3. It is shown that the areas with structural heterogeneity do not form colonies but are distributed stochastically in the section of welded joint, therefore, they do not decrease the general serviceability of welded joint. The sizes of such areas do not exceed the admissible values accepted by the standards for defects of welds produced in arc welding.

4. The presence of separate local dropouts of $K C V_{-40}$ values, observed during tests of welded joints produced using FBW, should not be considered as a rejecting sign.

1. Kuchuk-Yatsenko, S.I. (1986) Resistance butt welding of pipelines. Kiev: Naukova Dumka.

2. API STANDARD 1104: Welding of pipelines and related facilities. 21st ed.

3. $D N V-O S-F 101$ : Offshore standard. Submarine pipelines systems. Jan. 2000.

4. STO Gazprom 2-3.7-380-2009: Instruction on technology of welding of marine pipelines. Moscow.

5. Kuchuk-Yatsenko, S.I., Shvets, Yu.V., Zagadarchuk, V.F. et al. (2012) Flash-butt welding of thick-walled pipes from high-strength steels of K56 strength class. The Paton Welding J., 5, 2-7.

6. Kuchuk-Yatsenko, S.I., Shvets, Yu.V., Zagadarchuk, V.F. et al. (2013) Technology of heat treatment of pipe joints from steel of K56 grade produced by flash-butt welding. Ibid., 2, 2-7.

7. Kuchuk-Yatsenko, S.I., Kazymov, B.I., Zagadarchuk, V.F. et al. (1984) Formation of «dead spots» in joint produced by resistance welding. Avtomatich. Svarka, 11, 23-26.

8. STO Gazprom 22.4-359-2009: Instruction on non-destructive testing of welded joints in construction of land and underwater gas pipelines from steels X-80, $\mathrm{X}-100$. Moscow. 